American Journal of Applied Sciences 7 (7): 962-968, 2010

ISSN 1546-9239

(C) 2010 Science Publications

\title{
Synchronous Generator Disturbance Provoked by Induction Motor Starting
}

\author{
${ }^{1}$ S.P.Y. Santos, ${ }^{2}$ E. Delbone, ${ }^{2}$ E.F. Carvalho and ${ }^{3}$ L.N. Martins \\ ${ }^{1}$ Department of Electrical Engineering, Santa Cecilia University, UNISANTA, \\ Oswaldo Cruz Street 277, Santos, 11045-907, Brazil \\ ${ }^{2}$ Department of Electrical Engineering, Paulista University, UNIP, Sao Paulo, SP, Brazil \\ ${ }^{3}$ Department of Electrical Engineering, Federal University of Uberlandia, UFU, Uberlandia, MG, Brazil
}

\begin{abstract}
Problem statement: This study presented an alternative procedure for the starting of large Inductions Motors (IM) in isolated generation systems. Approach: In isolated generation systems on stand-by or base load, the starting of the IM provoked sags frequently beyond the ability of the other consumers in the plant to stand. Manufacturers' solutions always recommend a supersized generator to decrease transient reactance and achieve smaller sags. These calculation procedures were based on the theory presented by Beeman (1955). Instead of supersizing the generator, a good but expensive solution, the present authors had undertaken research into how to improve the Synchronous Generators (SG's) capacity to stand the start of IM without exceeding the field and armature temperature limits and with small sags. Results: The method utilized consisted of decreasing the response time of excitation, thus increasing Ceiling Voltage (CV). The advantage of this method besides leading to a reduction in the investment involved permits retrofitting in electrical plants already installed. Tests on updated industrial equipment whose CV of a $250 \mathrm{kVA}$ SG was increased from 2.7-5.4 were presented with their respective oscilographic records which show a reduction in sag from $40-34 \%$. With this solution was possible to start a 75 HP IM without supersize the SG. Conclusion: Computational simulations in MATLAB are also given and were compared with experimental results to validate the simulations. Models in the frequency and time domains are discussed.
\end{abstract}

Key words: Induction motors, synchronous generators, excitation, sag

\section{INTRODUCTION}

The analysis of the behavior of SGs shows that the inductive component of load is demagnetizing. In the starting of IM the current is large and inductive and provokes voltage sags (Penin, 2004; Gomez et al., 2004; Felce et al., 2004). To compensate for the decrease in flux and to recover the terminal voltage there are three actions in the rotor:

- The first reaction to compensate for the variation in the flux is provided by the damper winding located in the head of the poles (in salient poles in SGs), this takes a very short time, within just 2 or 3 cycles (Fitzgerald et al., 2003; Kundur, 1994)

- The second action is produced by the transformer effect of the main field winding and lasts 10-15 cycles (Fitzgerald et al., 2003; Kundur, 1994)

- The third action is due to the Excitation Regulation System; the action time depends on: the time constant T'do, the excitation type and the CV (Kundur, 1994; Zaso et al., 1994)

Before the 70's the Automatic Voltage Regulators (AVR) were electromechanical and the SG excitation was produced by a DC generator normally powered by the same main SG prime mover, often by the SG axle itself.

Therefore the excitation/regulation systems were very sluggish. On the other hand, the class $\mathrm{A}$ or $\mathrm{B}$ insulation established a large Short Circuit Ratio (SCR) and consequently small reactances. The SGs manufactured nowadays present smaller SCRs than the older SGs.

But in some cases the response to large inductive loads is faster in modern generators. This might appear to be a paradox: there could be SGs with smaller SCRs, but with smaller (i.e., better) response times. The sag could be bigger or smaller; it depends on the CV (ONSOperador, 2000). In other words, it is not only the

Corresponding Author: S.P.Y. Santos, Department of Electrical Engineering, Santa Cecilia University, UNISANTA, Oswaldo Cruz Street 277, Santos, 11045-907, Brazil Tel: 551332027100 Fax: 551332345297 
generator parameters that determine the response of the generator; it is also the excitation/regulation systems.

In the 60's and especially in the 70's, electromechanical AVRs were rapidly replaced by electronic ones. Electronic AVRs, for instance with tyristores, are very rapid. So the time response has now been reduced to some value between the transient and sub-transient response.

Besides that, the $\mathrm{CV}$ can be increased and therefore the current incremental rate could also be bigger. Consequently the time response could be smaller (better) even though the various time constants do not change (Fig. 3).

But, on the other hand, new insulating materials permit the reduction of the generator size and consequently there is an increase in the reactances and when synchronous reactances increase, regulation without AVR becomes worse.

This study demonstrates the possibility of starting a big IM without a supersized SG, just by increasing the CV.

\section{MATERIALS AND METHODS}

This research was carried out theoretically as according to classical approach i.e., in frequency domain as well as in time domain with math models like those used in computational simulations where not only the amplitude is calculated but also the duration.

Classical approach: In simplified classical models, in the frequency domain, the starting of the IM can be represented only by equivalent impedance:

$$
z_{e}=r_{s}+r_{r}+j\left(x_{s}+x^{\prime}{ }_{r}\right)
$$

Where:

$\mathrm{r}=$ Resistance of stator and rotor coils

$\mathrm{x}=$ Leakage reactance of stator and rotor coils

As the resistance part is frequently smaller than the reactive part, on the majority of occasions it is unnecessary to consider $r_{s}+r_{r}$. So the IM could be represented just by $x_{e}=x_{s}+x_{r}$. The $S G$ can be represented as an ideal source and a series reactance (if resistance is not considered). Thus the starting circuit could be represented as in Fig. 1.

In accordance with Beeman (1955), sag voltage in the SG could be represented as in Eq. 1:

$$
\mathrm{V}=\mathrm{x} /\left(\mathrm{x}+\mathrm{x}_{\mathrm{e}}\right)
$$

Where:

$\mathrm{x}=\mathrm{SG}$ transient or sub transient reactance as discussed later

$\mathrm{x}_{\mathrm{e}}=$ Reactance of IM

This modeling is used frequently by manufacturers and application engineers. The choice of reactance is difficult. What value should be used: $x{ }^{\prime}, x{ }_{d}$ or $\left(x^{\prime}{ }_{d}+\right.$ $\left.\mathrm{x}_{\mathrm{d}}\right) / 2$ ? Some manufacturers recommend $\mathrm{x}{ }_{\mathrm{d}}$ for Static Excitation (SE) and $\mathrm{x}^{\prime}{ }_{\mathrm{d}}$ for the $\mathrm{SG}$ with Rotating Excitation (RE). The SE has just one time constant, from the field (time constant of armature not considered) but Rotating Excitation, of the brushless type, has at least two time constants(exciter and main field). So the recovery time occurs within 5-15 cycles while in SE the recovery occurs within 3-5 cycles. Equation 1 does not take the influence of $\mathrm{CV}$ into consideration (Beeman, 1955). This aspect will be considered later on in this study.

No matter which reactance is chosen, transient or sub-transient, the results obtained from Eq. 1 do not present either accuracy or recovery time. Because the sensitivity of electrical devices to voltage variations is affected not only by the sag itself but also by the duration of the sag, the analysis of the disturbance is incomplete! Better forecasts could be obtained in computational simulations with Matlab that presents similar results with load tests. However before present models and simulations a briefing about some types of excitation is discussed.

Types of excitation: In accordance with IEEE 421.5 (1992), there are several types of excitation of SG. Figure 2 presents an SG with static excitation with a compound module; it corresponds to ST2A-Compound Source Rectifier Exciter, from IEEE 421.5, (1992).

The action of SE directly in the SG field gives a fast response and provides a smaller sag and recovery time than SG with RE. Other factors, such as CV, must be taken into consideration.

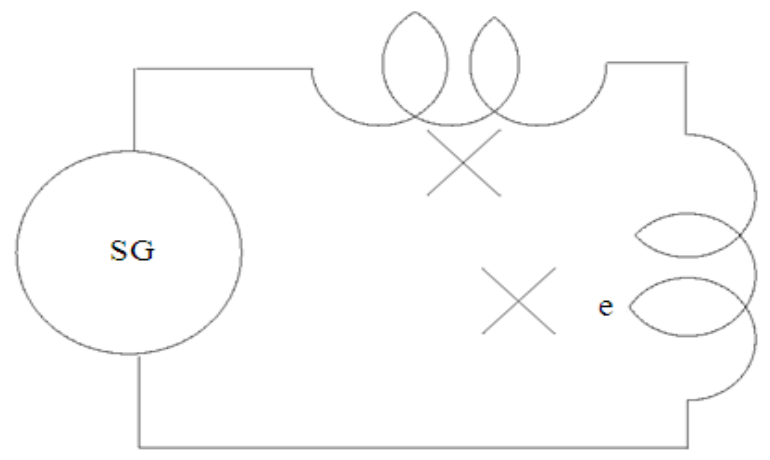

Fig. 1: SG feeding an IM R not considered 
The behavior of an SG/AVR during the starting of the IM is presented in Fig. 3: if the SG operates with no load, field current is $I_{\mathrm{fo}}$ and corresponds to the conduction angle $b_{0}<b_{1}$; if the generator feeds a partial load, the armature current (load current) is $\mathrm{I}_{\mathrm{L} 1}$ and the corresponding field current is $\mathrm{I}_{\mathrm{f} 1}$ and conduction angle will be b1; after starting the IM the SG's new load is supposedly nominal and will be $\mathrm{I}_{\mathrm{Ln}}$, the field current $\mathrm{I}_{\mathrm{fn}}$ and conduction angle will be b2. When the IM starts the current is $\mathrm{I}_{\mathrm{LS}}$ and the conduction angle will tend to $180^{\circ}$. Figure 3 (top) also presents the voltage sag when the load (IM) is applied and presents the behavior of the field current: with SE2 the voltage $\mathrm{V}_{\mathrm{SE}(\mathrm{CV} 2)}$ is maximum output voltage of exciter and $\mathrm{V}_{\mathrm{SE}(\mathrm{CV} 2)} / \mathrm{R}_{\mathrm{f}}$ is the maximum field current that the Excitation System could supply with the conduction angle fully opened.

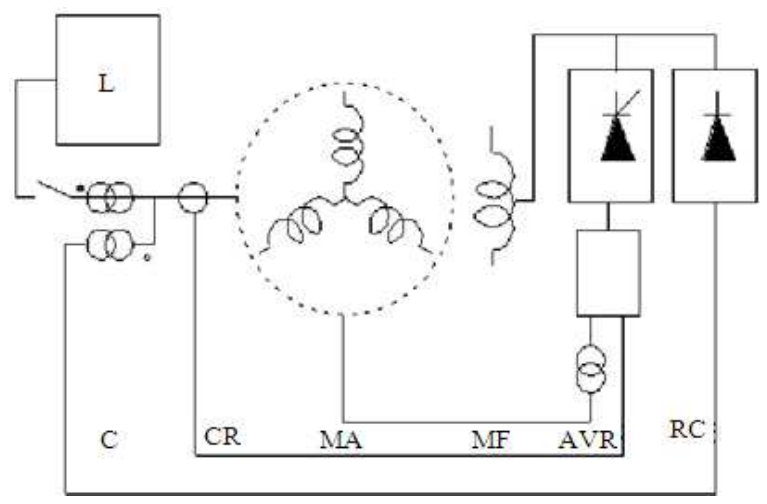

Fig. 2: SG with Static Excitation with AVR and compound

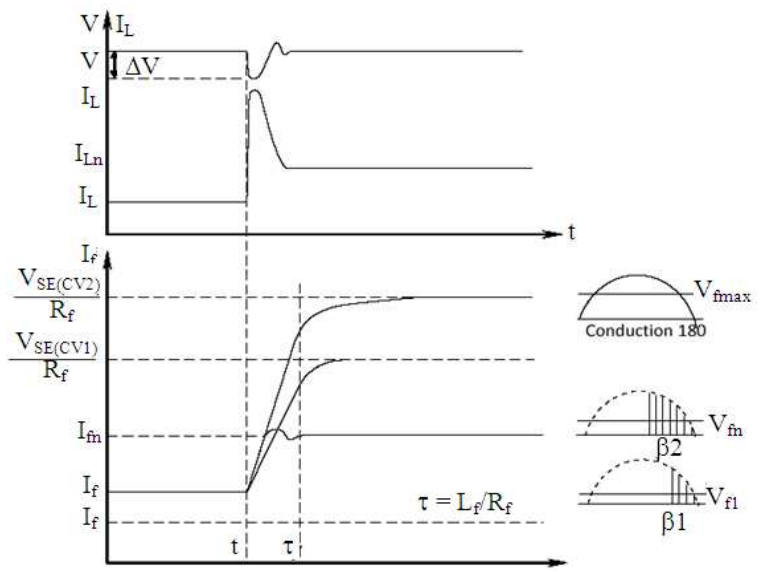

Fig. 3: Incremental rate of excitation system including regulator
With SE1 the voltage $\mathrm{V}_{\mathrm{SE}(\mathrm{CV} 1)}$ is maximum output voltage of exciter and $\mathrm{V}_{\mathrm{SE}(\mathrm{CV} 1)} / \mathrm{R}_{\mathrm{f}}$ is the maximum field current that the Excitation System could supply with the conduction angle fully opened. In the IM starting process, after reaching its maximum value, $I_{L S}$ load current decreases to $I_{L n}$ and $I_{f}$ is reduced, oscillating for some time, then stabilizing at $\mathrm{I}_{\mathrm{fn}}$. In Fig. 3 (bottom) the incremental rate of the field current with CV1 and CV2 are presented. It is evident that the higher the $\mathrm{CV}$ the faster the recovery time. The incremental rate could be called the slew rate, a phrase often used in amplifiers.

Damper and "transformer effect" of field: In load variations or in short circuits other variables, such as the contributions of damper and "transformer effect" of the field, must be taken into consideration.

Figure 4 presents a proposal for the simplification of a block diagram for a SE in accordance with Fig. 3, adapted from IEEE 421.5 (1992).

When load changes from $I_{L 1}$ to $I_{L 2}\left(\Delta I_{L}=I_{L 2}-I_{L 1}\right)$ the damper coil contributes with $\mathrm{I}_{\mathrm{kd}}=\mathrm{K}_{\mathrm{kd}} \cdot \mathrm{e}^{-\mathrm{t} / \mathrm{T}^{\prime} \mathrm{d}}$ :

$\mathrm{K}_{\mathrm{kd}}=\Delta \mathrm{I}_{\mathrm{L}} \cdot \mathrm{Ns} / \mathrm{N}_{\mathrm{kd}}$

Further, the main field contributes with $\Delta \mathrm{I}_{\mathrm{f}}$ (transformer effect) beyond $\mathrm{I}_{\mathrm{f}}$ :

$$
\begin{aligned}
& \Delta \mathrm{I}_{\mathrm{f}}=\mathrm{K}_{\Delta \mathrm{If}} \mathrm{e}^{-\mathrm{t} / \mathrm{T}^{\prime} \mathrm{d}} \\
& \mathrm{K}_{\Delta \mathrm{If}}=\Delta \mathrm{I}_{\mathrm{L}} \cdot \mathrm{Ns} / \mathrm{Nf}
\end{aligned}
$$

In Fig. 4 these values are represented by the blocks $\mathrm{K}_{\mathrm{kd}} /\left(\mathrm{s}+1 / \mathrm{T}{ }_{\mathrm{d}}\right)$ and $\mathrm{K}_{\Delta \mathrm{Ifd}}\left(\mathrm{s}+1 / \mathrm{T}_{\mathrm{d}}\right)$ (Ogata, 1996). Thus the real field current at $t=0+$ will be $\mathrm{I}_{\mathrm{f}}+\mathrm{I}_{\mathrm{kd}}+\Delta \mathrm{I}_{\mathrm{f}}$ where the last terms are load dependent only during the subtransient and transient periods.

The disadvantage of self-excited systems is the reduction of voltage in the supply of the exciterregulator system. Some manufacturers use a compensation system as presented in Fig. 2: when the current load increases, the compensator accordingly supplies more current for the field.

DC generators for excitation systems are no longer used. Nowadays most RE systems are brushless (Abdalla and Anwar, 2007). They can be self-excited or they can have a pilot exciter as in Fig. 5, where the pilot exciter is a Permanent Magnet Generator (PMG). The advantage of this kind of excitation is a smaller drop in the feeding of the AVR than in the self-excited system. 
Am. J. Applied Sci., 7 (7): 962-968, 2010

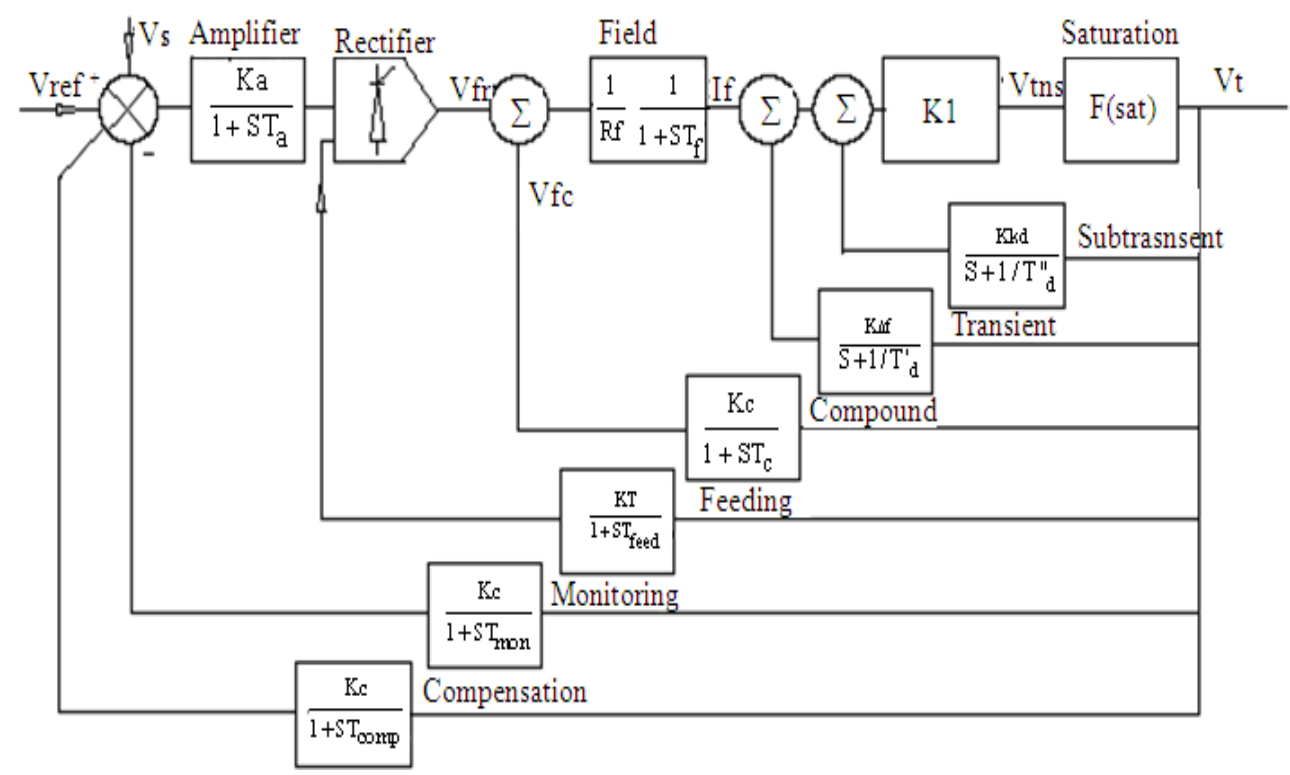

Fig. 4: Simplified block diagram of an SE

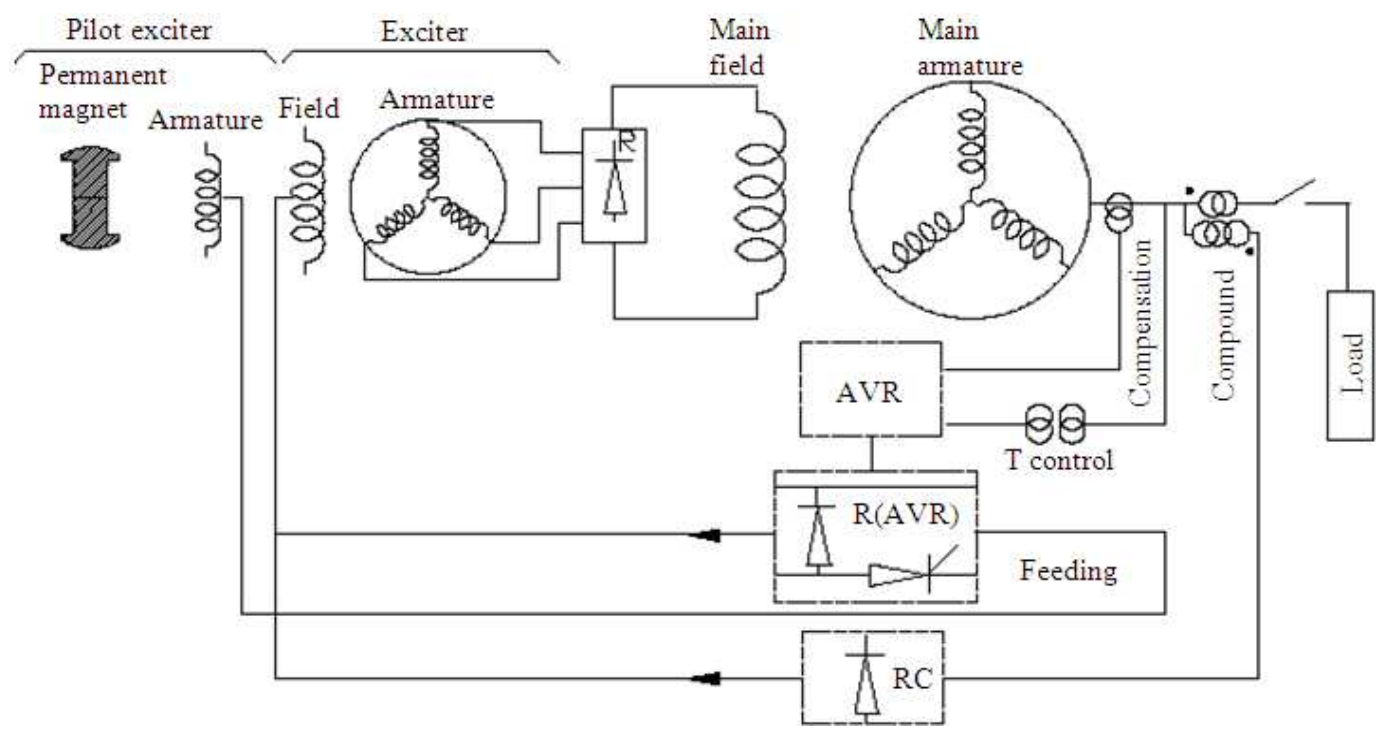

Fig. 5: Brushless RE with PMG corresponding to AC1A from IEEE 421.5 (1992)

It is supposed that in this kind of excitation at least three time constants are involved, besides the time constant of the regulator which is not normally taken into consideration: exciter field $\mathrm{T}_{\mathrm{fE}}$, armature $\mathrm{T}_{\mathrm{A}}$ (not considered) and main field $\mathrm{T}_{\mathrm{f}}=\mathrm{T}^{\prime}{ }_{\mathrm{do}}$. An independent source (PMG) feeds the AVR. Exciter field current $\mathrm{i}_{\mathrm{fE}}$ from the AVR may be represented as:

$\mathrm{i}_{\mathrm{fE}}=\mathrm{V}_{\mathrm{fE}} / \mathrm{R}_{\mathrm{fE}} \cdot\left(1-\mathrm{e}^{-\mathrm{t} / \mathrm{TEE}}\right)$
Field current from the compound (if connected) is:

$$
i_{f E C}=V_{f E C} / R_{f E} \cdot\left(1-e^{-t / T f E}\right)
$$

Where:

$\mathrm{V}_{\mathrm{fE}}=$ The voltage rectified from AVR

$\mathrm{V}_{\mathrm{fEc}}=$ The voltage from compound system (rectified)

When the exciter voltage output is $\mathrm{V}_{\mathrm{EAC}}=\mathrm{K}_{1} \cdot \mathrm{i}_{\mathrm{fE}}$ after rectification it will be $\mathrm{V}_{\mathrm{EDC}}=\mathrm{V}_{\mathrm{f}}$. 
Am. J. Applied Sci., 7 (7): 962-968, 2010

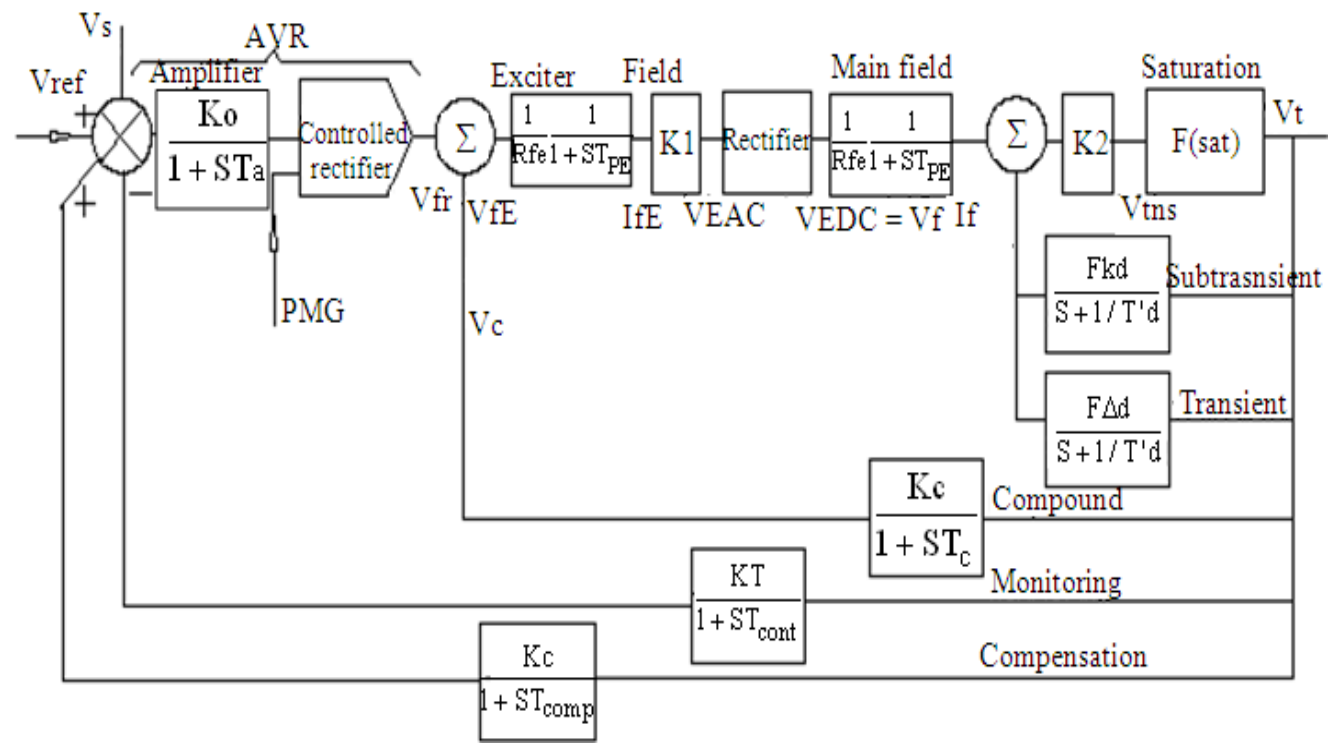

Fig. 6: Block diagram for rotating brushless type excitation

When $\mathrm{V}_{\mathrm{f}}$ is applied in the field, the field responds with $I_{f}$ with the time constant $T^{\prime}{ }_{d O}$. With a nonsaturated constant load terminal, voltage will be $\mathrm{V}_{\text {tns }}=$ $\mathrm{I}_{\mathrm{f}} \cdot \mathrm{K}_{2}$. When the load changes the damper coil and "transformer effect" of the field coil contribute with $\mathrm{I}_{\mathrm{kd}}$ and $\Delta \mathrm{I}_{\mathrm{f}}$ as previously stated:

$\mathrm{V}_{\mathrm{EDC}}=\mathrm{V}_{\mathrm{f}}=\mathrm{K}_{1} \cdot \mathrm{I}_{\mathrm{fE}}$

$\mathrm{i}_{\mathrm{f}}=\mathrm{V}_{\mathrm{f}} / \mathrm{R}_{\mathrm{f}} \cdot\left(1-\mathrm{e}^{-\mathrm{t} / \mathrm{Tf}}\right)$

So the recovery time is longer than in the SE systems. In this case (SE), some manufacturers propose the use of $x^{\prime \prime}{ }_{d}$, instead of $x_{d}{ }_{d}$, in Eq. 1.

In a system with PMG there is a voltage drop in AVR feeding when the load is applied in the SG, but it is smaller than in the self-excited systems. Figure 6 presents a block diagram for the RE brushless type with an auxiliary exciter with PMG, corresponding to a simplified AC1A (IEEE 421-5, 1992). In rated load conditions there is a corresponding field current. This value might only be exceeded for a short time to avoid going beyond the thermal limit. ANSI Standard C50.13 (1977) and Ong (1998) establishes limits for the field winding of round rotor generators in accordance with the following points:

$\begin{array}{llllll}\text { Time (sec) } & 5 & 10 & 30 & 60 & 120 \\ \text { Field current } & 300 & 208 & 146 & 125 & 112\end{array}$

The excitation limiter detects any excessive field current and diminishes to the value previously established.

Models for simulation: The classical approach presented good results in steady state situations but not in transient ones. Computational simulations present values in the time domain. The models in $\mathrm{dq} 0$ proposed by Park in 1929 and used nowadays in several software programs such as Matlab (Simulink) relate all the stator parameters to the direct and quadrature axes which turn with the rotor axis (Ong, 1998).

This study also proposes an abc model to simulate the SG's behavior (Penin, 2004). The results are good with both the dq0 and abc models. However, the processing of the dq0 model is three times faster than that of the abc model proposed. The processing of the abc model calls for the calculation of the matrix of differential equations with variable components.

The abc model's voltage is represented by:

$$
\left[\mathrm{v}_{\mathrm{i}}\right]=\left[\mathrm{r}_{\mathrm{i}}\right] \cdot\left[\mathrm{i}_{\mathrm{i}}\right]+\left[\mathrm{L}_{\mathrm{ij}}\right] \mathrm{d}\left[\mathrm{i}_{\mathrm{i}}\right] / \mathrm{dt}+\left[\mathrm{i}_{\mathrm{i}}\right] \cdot \mathrm{d}\left[\mathrm{L}_{\mathrm{ij}}\right] / \mathrm{dt}
$$

where $i$ and $\mathrm{j}$ can represent stator and (or) rotor coils. For the phase "a" the expression (8) may be expressed as:

$$
\begin{aligned}
\mathrm{V}_{\mathrm{a}}= & \mathrm{r}_{\mathrm{s}} \mathrm{i}_{\mathrm{s}}+\mathrm{L}_{\mathrm{aa}} \cdot \mathrm{pi}_{\mathrm{a}}+\mathrm{i}_{\mathrm{a}} \mathrm{pL_{ \textrm {aa } }}+\mathrm{L}_{\mathrm{ab}} \mathrm{pi}_{\mathrm{b}}+\mathrm{i}_{\mathrm{b}} \cdot \mathrm{pL}_{\mathrm{ab}} \\
& +\mathrm{L}_{\mathrm{ac}} \mathrm{pi}_{\mathrm{c}}+\mathrm{i}_{\mathrm{c}} \mathrm{pL_{ \textrm {ac } }}+\mathrm{LL}_{\mathrm{af}}+\mathrm{pi}_{\mathrm{f}}+\mathrm{i}_{\mathrm{f}} \mathrm{pL}_{\mathrm{af}} \\
& +\mathrm{L}_{\mathrm{akd}} \mathrm{pi}_{\mathrm{kd}}+\mathrm{i}_{\mathrm{kd}} \mathrm{pL_{ \textrm {akd } }}+\mathrm{L}_{\mathrm{akd}} \mathrm{pi}_{\mathrm{kq}}+\mathrm{i}_{\mathrm{kq}} \mathrm{L}_{\mathrm{akq}}
\end{aligned}
$$


The elements $\mathrm{L}$ are a function of the rotor angle (except rotor inductances) and therefore are a time function: they vary with the rotation of the rotor. So the solution of phase quantities directly is very difficult because of these time-dependent coefficients. In order to calculate phase current from flux linkages it is necessary to compute the inductance matrix for every time step, but as inductances are time-dependent the computation of the inverse matrix is time-consuming and problems of numerical stability could result.

The dq0 Park model is well known: after relating stator values to rotor axes $\mathrm{d}$ and $\mathrm{q}$ and adding zero sequence the following set of equations is produced:

- Equation 10 is in accordance with Ong (1998) and Simulink MATLAB:

$$
\begin{aligned}
& \left.\mathrm{v}_{\mathrm{q}}=\mathrm{r}_{\mathrm{s}} \mathrm{i}_{\mathrm{q}}+\mathrm{p} \theta_{\mathrm{r}}\left(\mathrm{i}_{\mathrm{d}}\left(\mathrm{L}_{\mathrm{md}}+\mathrm{L}_{\mathrm{ls}}\right)+\mathrm{L}_{\mathrm{md}} \mathrm{i}_{\mathrm{f}}{ }_{\mathrm{f}}+\mathrm{L}_{\mathrm{md}} \mathrm{i}_{\mathrm{kd}}{ }\right)\right) \\
& +\mathrm{p}\left(\left(\left(\mathrm{L}_{\mathrm{mq}}+\mathrm{L}_{\mathrm{ls}}\right) \mathrm{i}_{\mathrm{q}}+\mathrm{L}_{\mathrm{md}} \mathrm{i}_{\mathrm{kq}}{ }^{\prime}\right)\right. \\
& \mathrm{v}_{\mathrm{d}}=\mathrm{r}_{\mathrm{s}} \cdot \mathrm{i}_{\mathrm{d}}-\mathrm{p} \theta_{\mathrm{r}}\left(\mathrm{i}_{\mathrm{q}}\left(\mathrm{L}_{\mathrm{mq}}+\mathrm{L}_{\mathrm{ls}}\right)+\mathrm{L}_{\mathrm{mq}} \mathrm{i}_{\mathrm{kq}}{ }^{\prime}\right) \\
& +\mathrm{p}\left(\mathrm{i}_{\mathrm{d}}\left(\mathrm{L}_{\mathrm{md}}+\mathrm{L}_{\mathrm{ls}}\right)+\mathrm{L}_{\mathrm{md}} \mathrm{i}_{\mathrm{f}}{ }_{\mathrm{f}}+\mathrm{L}_{\mathrm{md}} \mathrm{i}{ }_{\mathrm{kd}}\right) \\
& \mathrm{v}_{0}=\mathrm{r}_{\mathrm{s}} \mathrm{i}_{0}+\mathrm{pi}_{0} \mathrm{~L}_{\mathrm{ls}}
\end{aligned}
$$

- Equation 11 in accordance with Kundur (1994):

$$
\begin{aligned}
\mathrm{e}_{\mathrm{q}}= & -\mathrm{R}_{\mathrm{a}} \cdot \mathrm{i}_{\mathrm{q}}+\omega \mathrm{r}\left(-\mathrm{i}_{\mathrm{d}} \mathrm{L}_{\mathrm{d}}+\mathrm{L}_{\mathrm{afd}} \mathrm{i}_{\mathrm{fdd}}+\mathrm{L}_{\mathrm{akd}} \mathrm{i}_{\mathrm{kd}}\right) \\
& +\mathrm{p}\left(-\mathrm{L}_{\mathrm{q}} \mathrm{i}_{\mathrm{q}}+\mathrm{L}_{\mathrm{akq}} \mathrm{i}_{\mathrm{kq}}\right) \\
\mathrm{e}_{\mathrm{d}}= & -\mathrm{R}_{\mathrm{a}} \cdot \mathrm{i}_{\mathrm{d}}-\omega \mathrm{r}\left(-\mathrm{i}_{\mathrm{q}} \mathrm{L}_{\mathrm{q}}+\mathrm{L}_{\mathrm{akq}} \mathrm{i}_{\mathrm{kq}}\right) \\
& +\mathrm{p}\left(-\mathrm{i}_{\mathrm{d}} \mathrm{L}_{\mathrm{d}}+\mathrm{L}_{\mathrm{afd}} \mathrm{i}_{\mathrm{fd}}+\mathrm{L}_{\mathrm{akd}} \mathrm{i}_{\mathrm{kd}}\right) \\
\mathrm{e}_{0}= & -\mathrm{R}_{\mathrm{a}} \cdot \mathrm{i}_{0}-\mathrm{pL}_{0} \mathrm{i}_{0} \omega \mathrm{r}
\end{aligned}
$$

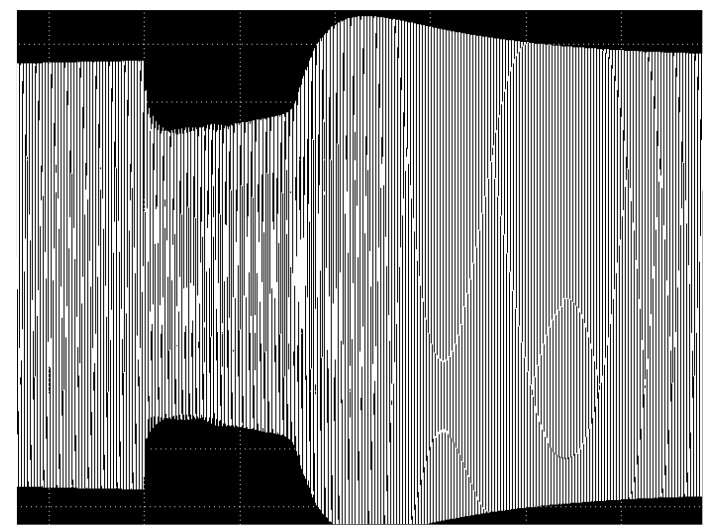

Fig. 7: Computational simulation: Sag of voltage in the starting of the 75 HP IM
Expressions (10) and (11) have the same meaning although some + and - signs have been changed because different references have been adopted.

Computational simulation: The computational processing of $250 \mathrm{kVA}$ SG feeding IM 1 of $40 \mathrm{HP}$ and starting IM 2 of 75 HP results

With CV of 2,7:

Sag of $38,8 \%$

With a CV of 5.4:

Sag of $31-32 \%$ (Fig. 7)

Parameters of the machines are:

SG of $250 \mathrm{kVA}$ :

$\mathrm{x}_{\mathrm{d}}=2.5 ; \mathrm{x}_{\mathrm{l}}=0.084 ; \mathrm{x}_{\mathrm{q}}=1.8 ; \mathrm{x}_{\mathrm{d}}=0.22 \mathrm{x}_{\mathrm{d}}=0.12 ;$

$\mathrm{x}_{\mathrm{q}}=0.09 ; \mathrm{T}{ }_{\mathrm{d} 0}=4 ; \mathrm{T}{ }_{\mathrm{d} 0}=0.0309 \mathrm{~T}{ }_{\mathrm{q}}=0.0259 ;$

$r_{\mathrm{s}}=0.003$

IM 1 of $40 \mathrm{HP}$ :

$\mathrm{r}_{\mathrm{s}}=0.122 \mathrm{x}_{\mathrm{s}}=0.262 \mathrm{r}_{\mathrm{r}}^{\prime}=0.083 \mathrm{x}_{\mathrm{r}}^{\prime}=0.632 \mathrm{x}_{\mathrm{m}}=13.26$

IM 2 of 75 HP:

$\mathrm{r}_{\mathrm{s}}=0.048 \mathrm{x}_{\mathrm{s}}=0.1019 \mathrm{r}_{\mathrm{r}}{ }^{\prime}=0.0315, \mathrm{x}_{\mathrm{r}}{ }^{\prime}=0.2397$

$\mathrm{x}_{\mathrm{m}}=16.26$

In this simulation the value of the $\mathrm{CV}$ was 2.7 .

\section{RESULTS AND DISCUSSION}

Experimental field results: Experimental results of $250 \mathrm{kVA}$ SG feeding IM 1 of $40 \mathrm{HP}$, starting IM 2 of 75 HP with the same parameters of computational simulation presents sag $40 \%$ with recovery time of 55 $\mathrm{Hz}$ or $0.9 \mathrm{sec}$.

The analysis of Fig. 8 confirms values similar to those simulated. Magnetic switch opens after some cycles then voltage increases, the magnetic switch closes voltage decreases and the magnetic switch opens again. The IM started but contacts of magnetic switch might be destroyed.

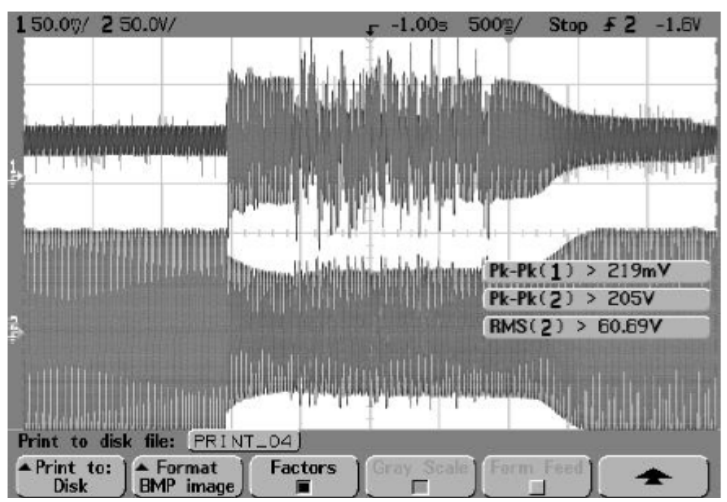

Fig. 8: Experimental result: sag of voltage in the starting of the $75 \mathrm{HP}$ IM with a CV of 2.7 


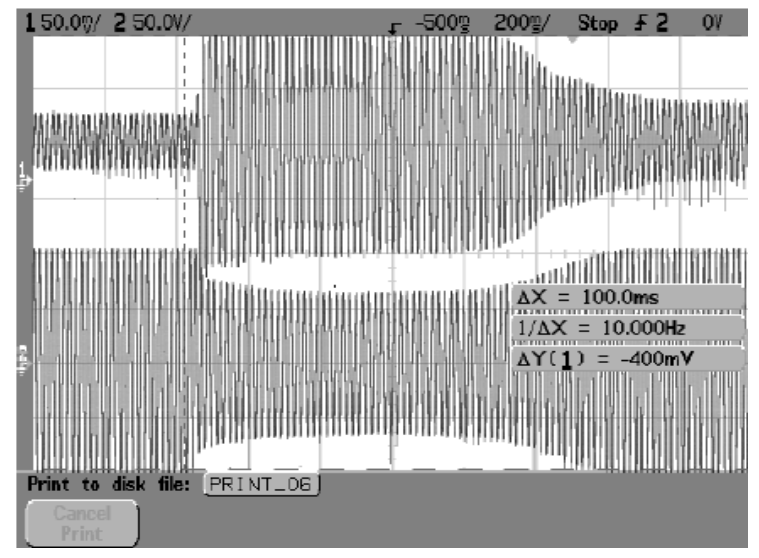

Fig. 9: Experimental result: sag of voltage in the starting of the 75 HP IM with a CV of 5.4

\begin{tabular}{lll}
\multicolumn{3}{l}{ Table 1: Resume of Simulation and experimental results } \\
\hline $\begin{array}{l}\text { Results of } \\
\text { simulation (Fig. 7) }\end{array}$ & $\begin{array}{l}\text { Experimental } \\
\text { results (Fig. 8) }\end{array}$ & $\begin{array}{l}\text { Experimental } \\
\text { results (Fig. 9) }\end{array}$ \\
\hline $\mathrm{CV}=5.4$ & $\mathrm{CV}=2.7$ & $\mathrm{CV}=5.4$ \\
$\Delta \mathrm{V}=31-32 \%$ & $\Delta \mathrm{V}=40.0 \%$ & $\Delta \mathrm{V}=34 \%$ \\
Overshoot $=32 \%$ & No overshoot & No overshoot \\
\hline
\end{tabular}

Figure 9 is the record of starting for the same SG and IM. However, in this test, the field coils have been grouped in parallel so the field's voltage is reduced by half and the current is twice the original one. So with the same excitation regulation system the ceiling voltage is 5.4 instead of 2.7 .

\section{CONCLUSION}

Problems provoked by starting of IM are often mainly in distributed generation. If the SGs, one or several in parallel work without connection with main the sag will be larger and it is recommendable monitoring in real-time (Simoes, 2007). As has been demonstrated above, the improvement in the starting of IMs can be achieved in several ways. Several manufacturers prefer to over-size the SG to obtain smaller reactance, but this means greater investment. In this study it has been demonstrated that there are solutions which improve the starting of IMs by using appropriate excitation systems which increase the CV. A summary is presented in the Table 1 .

\section{REFERENCES}

Abdalla, A.N. and A. Anwar, 2007. Simulation model of brushless excitation system. J. Applied Sci., 7: 1186-1190. DOI: 10.3923/jas.2007.1186.1190

ANSI Standard C50.13, 1977. Posting in the Eng-Tips forums is a member-only feature. http://www.engtips.com/viewthread.cfm?qid=270724\&page $=1$
Beeman, D., 1955. Industrial Power Systems Handbook. MacGraw-Hill Book Company, New York, ISBN: 10 0-07-004301-9.

Felce, A., G. Matas and Y. Da Silva, 2004. Voltage sag analysis and solution for an industrial plant with embedded induction motor. Proceeding of the 39th IAS Annual Meeting Industry Applications Conference, Oct. 3-7, IEEE Xplore Press, USA., pp: 2573-2578. DOI: 10.1109/IAS.2004.1348838

Fitzgerald, A.E., J.R.C. Kingsley and S.D. Umans, 2003. Electric Machinery. McGraw-Hill Companies-6/e, ISBN: 0-07-366009-4.

Gomez, J.C., C. Reineri, G. Campetelli and M.M. Morcos, 2004. A study of voltage sags generated by induction motor starting. Elect. Power Comp. Syst., 32: 645-653. DOI: $10.1080 / 15325000490228423$

IEEE 421.5, 1992. Recommended practice for excitation system models for power systems stability studies. IEEE, NY., pp: 21-22. http://electronics.ihs.com/document/abstract/BWM VCAAAAAAAAAAA

Kundur, P., 1994. Power System Stability and Control. MacGraw-Hill, New York, ISBN: 0-07-035958-X, pp: 1176.

Ogata, K., 1996. Modern Control Engineering. 3rd Edn., Prentice-Hall, New Jersey, ISBN: 0-13227307-1, pp: 997.

Ong, C.M., 1998. Dynamic Simulation of Electric Machinery. Prentice Hall PTR, New Jersey, USA., ISBN: 0-13-723785-5.

ONS-Operador, 2000. Nacional do Sistema Elétrico Submódulo 3.6 Requisitos técnicos mínimos para a Conexão à Rede Básica. http://www.ons.org.br/download/procedimentos/m odulos/Modulo_3/Submodulo\%203.6_Rev_1.0.pdf

Penin, S.S., 2004. Disturbances in synchronous generators in isolated generation. Master Dissertation. Universidade Federal de Uberlândia. http://www.acervobiblioteca.ufu.br:8000/cgibin/gw_46_4_2/chameleon

Simoes, C.A., 2007. Real-time monitoring of distributed generation based on state estimation and hypothesis testing. Proceeding of the Power Tech, 2007 IEEE Lausanne, July 1-5, IEEE Xplore Press, Lausanne, pp: 538-543. DOI: 10.1109/PCT.2007.4538374

Zaso, A., J.L. Zamora, L. Rouco and F.L. Pagola, 1994 Identification of excitation systems from time response tests. Proceeding of the International Conference on Control, Mar. 21-24, IEEE Xplore Press, Coventry, UK., pp: 839-844. DOI 10.1049/cp:19940242 